\title{
Seismogenic Deformation Between the Sierran Microplate and Oregon Coast Block, California
}

\author{
Jeffrey Unruh \\ Lettis Consultants International, Inc., 1981 North Broadway, Suite 330, Walnut Creek, CA 94596 \\ James Humphrey
}

Lahontan GeoScience, Inc. 10775 Double R BIvd., Reno, NV 89521

\section{Supplemental Material}

\section{Earthquake Relocation}

To prepare a catalog of earthquake sources we developed ad hoc seismic velocity models for the study region, calculated the hypocentral locations of selected earthquakes using the velocity models, relocated these earthquakes again using the double-difference technique (Waldhauser and Ellsworth, 2000; Waldhauser, 2001) to improve the precision of the locations, and then calculated the focal mechanisms of well-observed events to determine the style of faulting. The starting earthquake catalog was obtained from the Northern California Earthquake Data Center (NCEDC) at the Berkeley Seismological Laboratory based on data recorded by the Northern California Seismic Network (NCEDC, 2014). This catalog contained approximately 14,000 instrumentally-recorded earthquakes located in a region extending from latitude $42.15^{\circ} \mathrm{N}$ to $39.9^{\circ} \mathrm{N}$ and longitude $120.5^{\circ} \mathrm{W}$ to $122.8^{\circ} \mathrm{W}$ for the time period 1973 through 2011 (Figure S1). The magnitudes of the earthquakes ranged from 0 to 5.2 with a median magnitude of 1.6. Although the focal depths range from 0 to $83 \mathrm{~km}$, only those events located above $30 \mathrm{~km}$ are used in the analysis to maintain focus on seismogenic deformation in the upper crust. The deeper earthquakes are generally related to deformation of the subducting Gorda plate.

The first step in developing more precise hypocenter locations was to create ad hoc velocity models appropriate for the structure of the upper crust, spatial distribution of the earthquakes, and coverage by the seismograph stations. A fundamental assumption in the double-difference approach to earthquake location is that the crust in the volume surrounding the earthquakes is laterally homogeneous. Because the crust in northern California is very heterogeneous it was necessary to divide the study area into six sub regions (velocity domains) based on the similarity in P-wave velocity at hypocentral depths (Figure S2). A regional three-dimensional tomographic model of the P-wave velocity structure in Northern California (Thurber et al., 2009) was used to develop one-dimensional starting velocity models for each of the velocity domains that were modified in subsequent iterations (Figure S2). For each velocity domain a starting model was constructed using the average velocity from each of the seven depths $(1,4$, $8,14,20,28$ and $36 \mathrm{~km}$ below sea level) from Thurber et al. (2009). Each starting model was expanded from 7 to 21 layers by linearly interpolating the velocities between the seven depths in the 3-D model. Two-kilometer-thick layers were used for the upper and middle crust and four-kilometer-thick layers for the lower crust and upper mantle. A joint hypocenter determination (JHD) algorithm (VELEST; Kissling et al., 1994) was used to simultaneously invert travel times for hypocenter location, velocity structure and station corrections for each domain except MP (Modoc Plateau) where insufficient data and seismograph coverage precluded the development of an ad hoc model. The final velocity models derived for each domain are summarized in Figure S3. The spread in P-wave velocities in the upper $5 \mathrm{~km}$ is most 
likely due to the variation in near surface geology throughout the region. The velocities between 5 and $20 \mathrm{~km}$ depth are similar among all the domains except the northern Sacramento Valley (NSV in Figure S2). Higher P-wave velocities in the NSV domain are probably due to mafic rocks underlying the Klamath Mountains block north of Shasta Lake and the Great Valley ophiolite, which extends from about $7 \mathrm{~km}$ to $30 \mathrm{~km}$ in depth in the area south of Shasta Lake (Thurber et al., 2009). Below about $30 \mathrm{~km}$ the higher velocities in the NSV domain may reflect the influence of the subducted Gorda slab. These ad hoc velocity models were used in the next phase of the analysis, the double difference inversion, to produce more precise hypocentral locations.

Using the improved velocity models and the JHD earthquake locations as input, more precise relative event locations were calculated using the double-difference algorithm. This algorithm takes advantage of the fact that, if the hypocentral separation between two earthquakes is small compared to the eventstation distance and the scale length of velocity heterogeneity, then rays traveling between the source region and a common station are similar along almost the entire ray path (Waldhauser and Ellsworth, 2000). The difference in travel times for two closely spaced events observed at one station can be attributed to the spatial offset between the events. Therefore, pairs of closely spaced events can be located very precisely and linear trends in diffuse clusters of seismicity (presumably related to slip on a single fault) can be highlighted.

Earthquake epicenters relocated using the double-difference algorithm are shown in Figure S4. These earthquakes were recorded on at least eight seismograph stations and formed a network of event pairs observed on at least six stations. As such, only a small subset of the events in the NCEDC catalog (Figure S1) is shown in Figure S5. These event locations are more precise than the single event locations shown in Figure S1, improve the reliability of the focal mechanisms and highlight patterns in seismicity that indicate the orientation of seismically active structures. Examples are the north-northwest and northwest trends of epicenters in the Lake Almanor area that are parallel to some Quaternary faults and west-northwest alignments of epicenters that parallel topographic features in the Sierra - Cascade Boundary Zone (Sawyer, 2013). Clusters of repeating earthquakes occur around volcanic centers such as Lassen Peak, the southeast flank of Mt. Shasta, Stephens Pass, and Medicine Lake. There are significant clusters of earthquakes around Shasta Lake, including the 1998 ML5.2 earthquake sequence near Redding, and in the area east of the Sacramento River between Redding and Red Bluff.

\section{Results of the Kinematic Inversion of Seismic P \& T axes}

The results from the inversion of the $P$ and $T$ axes from the focal mechanisms of the relocated hypocenters described above are summarized in Table S1 and shown in Figure 3 of the main text. Table S1 lists the regional strain domains and summarizes the inversion results for each. Columns labeled $d_{1}$ and $d_{3}$ describe orientation of the principal strain rates ( $d_{1}$ lengthening). Columns $D, W$ and $V$ describe the deformation-rate parameter, the vorticity parameter and the net vertical deformation parameter, respectively. Column COS-1 describes the inverse mean cosine misfit of the solution, which provides an estimate of the goodness of fit for the inversion results. Column $\mathrm{N}$ indicates the inversion sample size for a particular domain. The final column lists the orientation of the derived maximum dextral shear rate for each domain. The inversion parameters are discussed in the main text and in more detail in the cited references. 


\section{Differential Motion Between the Sierran Microplate and the Oregon Coast block}

An updated SN-OCB Euler pole predicts that the northern Sacramento Valley moves about $5 \mathrm{~mm} / \mathrm{yr}$ toward $\mathrm{N} 70^{\circ} \mathrm{W}$ relative to the southern Klamath Mountains in Oregon (R. McCaffrey, personal communication, 2016). This relative motion also can be inferred by comparing the velocities (relative to stable North America) of GPS stations on the Sierran microplate in the northern Sacramento Valley with those in the southern Klamath Mountains on the Oregon Coast Block (Figure S5). Although the raw GPS velocities in Figure S5 have not been corrected for transient elastic strain from the locked Cascadia subduction zone, and thus do not precisely reflect permanent crustal deformation, the resultant velocity between the two groups of stations is directed WNW-ESE, suggesting that the crust between the rigid parts of the Sierran microplate and Oregon Coast Block is being subjected to approximately WNWdirected dextral shear to accommodate the differential motion.

\section{$\underline{\text { References }}$}

Kissling, E., Ellsworth, W. L., Eberhart-Phillips, D., and U. Kradolfer: Initial reference models in local earthquake tomography, J. Geophys. Res., 99, 19'635-19'646, 1994.

NCEDC (2014), Northern California Earthquake Data Center. UC Berkeley Seismological Laboratory. Dataset. doi:10.7932/NCEDC.

Sawyer, T.L., 2013, The northern California shear zone-missing link in the Pacific-North American plate transform margin: Geological Society of America Abstracts with Programs, v. 45, no. 6, p. 59.

Thurber, C., H. Zhang, T. Brocher, and V. Langenheim, 2009, Regional three-dimensional seismic velocity model of the crust and uppermost mantle of northern California, Journal of Geophysical Research, v. 114, B01304.

Waldhauser, F., and W. L. Ellsworth, A double-difference earthquake location algorithm: Method and application to the northern Hayward fault, California, Bulletin of the Seismological Society of America, $v$. 90, p. 1353-1368, 2000.

Waldhauser, F., HypoDD: A computer program to compute double-difference earthquake locations, USGS Open File Rep., 01-113, 2001. 
Table S1 Kinematic Inversion Results

\begin{tabular}{|c|c|c|c|c|c|c|c|c|}
\hline Domain Name $^{a}$ & $\begin{array}{l}\text { d1 (trend, } \\
\text { plunge) }\end{array}$ & $\begin{array}{l}\text { d3 (trend, } \\
\text { plunge) }\end{array}$ & D & w & $\mathbf{v}$ & $\begin{array}{l}\text { Cos-1(Mean } \\
\text { Cos Error) }\end{array}$ & $\begin{array}{c}\text { Number of } \\
\text { data }\end{array}$ & $\begin{array}{c}\text { Maximum dextral shear rate } \\
\text { (strike/dip/rake) }\end{array}$ \\
\hline Western Sierra Nevada (WSNF) & $71,-17$ & 134,57 & 0.47 & 0.28 & -0.6 & 11.89 & 44 & $\mathrm{~N} 53^{\circ} \mathrm{W} / 37^{\circ} \mathrm{NE} / 23^{\circ} \mathrm{E}$ \\
\hline Sierra-Cascade Boundary 1 (SBZ1) & 86,11 & $175,-4$ & 0.56 & -0.02 & 0.11 & 13.39 & 123 & $\mathrm{~N} 50^{\circ} \mathrm{W} / 79^{\circ} \mathrm{SW} / 5^{\circ} \mathrm{NW}$ \\
\hline Sierra-Cascade Boundary 2 (SBZ2) & 66,2 & 156,9 & 0.56 & 0.03 & 0.06 & 6.67 & 62 & $\mathrm{~N} 69^{\circ} \mathrm{W} / 85^{\circ} \mathrm{NE} / 8^{\circ} \mathrm{SE}$ \\
\hline Tehama (TEHA) & $91,-37$ & 163,23 & 0.54 & -0.10 & 0.24 & 12.26 & 42 & $\mathrm{~N} 59^{\circ} \mathrm{W} / 45^{\circ} \mathrm{NE} / 9^{\circ} \mathrm{NW}$ \\
\hline West Lake Almanor (WLKA) & 114,22 & $195,-20$ & 0.52 & -0.07 & 0.04 & 9.44 & 84 & $\mathrm{~N} 25^{\circ} \mathrm{W} / 59^{\circ} \mathrm{SW} / 1^{\circ} \mathrm{NW}$ \\
\hline Lake Almanor (LKAL) & 76,4 & 338,61 & 0.60 & 0.21 & -0.84 & 10.46 & 79 & $\mathrm{~N} 41^{\circ} \mathrm{W} / 48^{\circ} \mathrm{SW} / 35^{\circ} \mathrm{W}$ \\
\hline Lassen (LASS) & 99,13 & $178,-38$ & 0.56 & 0.08 & -0.30 & 8.58 & 92 & $\mathrm{~N} 34^{\circ} \mathrm{W} 53^{\circ} \mathrm{SW} / 15^{\circ} \mathrm{NW}$ \\
\hline Viola (VIOL) & 110,33 & $167,-39$ & 0.45 & -0.84 & -0.09 & 4.47 & 57 & $\mathrm{~N} 38^{\circ} \mathrm{W} / 33^{\circ} \mathrm{SW} / 4^{\circ} \mathrm{NW}$ \\
\hline Whitmore (WHIT) & 65,4 & 333,28 & 0.34 & 0.05 & -0.32 & 8.44 & 58 & $\mathrm{~N} 68^{\circ} \mathrm{W} / 68^{\circ} \mathrm{SW} / 16^{\circ} \mathrm{NW}$ \\
\hline Bear Creek (BRCK) & $54,-61$ & 114,16 & 0.45 & 0.33 & 0.68 & 13.40 & 71 & $\mathrm{~N} 54^{\circ} \mathrm{E} / 36^{\circ} \mathrm{NW} / 25^{\circ} \mathrm{W}$ \\
\hline Redding 1 (RED1) & $49,-40$ & 116,26 & 0.52 & -0.09 & 0.23 & 11.75 & 107 & $\mathrm{~N} 76^{\circ} \mathrm{E} / 41^{\circ} \mathrm{NW} / 8^{\circ} \mathrm{W}$ \\
\hline Redding 2 (RED2) & $52,-11$ & 142,0 & 0.54 & 0.36 & 0.09 & 11.73 & 159 & $\mathrm{~N} 83^{\circ} \mathrm{W} / 82^{\circ} \mathrm{N} / 8^{\circ} \mathrm{E}$ \\
\hline Southern Hat Creek Graben (SHCG) & $77,-16$ & 0,52 & 0.58 & 0.26 & -0.75 & 10.11 & 76 & $\mathrm{~N} 48^{\circ} \mathrm{W} / 69^{\circ} \mathrm{SW} / 49^{\circ} \mathrm{NW}$ \\
\hline Shasta Lake (SHLK) & $44,-2$ & 133,6 & 0.42 & 0.13 & -0.11 & 11.72 & 129 & $\mathrm{~N} 89^{\circ} \mathrm{E} / 85^{\circ} \mathrm{N} / 3^{\circ} \mathrm{E}$ \\
\hline West Burney (WBRN) & 51,33 & $126,-22$ & 0.51 & 0.03 & 0.16 & 10.12 & 53 & $\mathrm{~N} 85^{\circ} \mathrm{E} / 50^{\circ} \mathrm{S} / 7^{\circ} \mathrm{E}$ \\
\hline Burney (BURN) & $68,-10$ & 155,12 & 0.45 & -0.01 & -0.07 & 7.87 & 61 & $\mathrm{~N} 68^{\circ} \mathrm{W} / 74^{\circ} \mathrm{NE} / 2^{\circ} \mathrm{SE}$ \\
\hline Iron Canyon (ICAN) & $65,-1$ & 155,8 & 0.46 & 0.27 & -0.06 & 10.29 & 48 & $\mathrm{~N} 69^{\circ} \mathrm{W} / 84^{\circ} \mathrm{NE} / 5^{\circ} \mathrm{SE}$ \\
\hline Northern Hat Creek Graben (NHCG) & $75,-9$ & $166,-4$ & 0.52 & 0.16 & 0.04 & 7.49 & 40 & $\mathrm{~N} 60^{\circ} \mathrm{W} / 86^{\circ} \mathrm{NE} / 9^{\circ} \mathrm{NW}$ \\
\hline South Shasta (SSHA) & 77,16 & 322,56 & 0.71 & 0.47 & -0.75 & 8.30 & 58 & $\mathrm{~N} 48^{\circ} \mathrm{W} / 39^{\circ} \mathrm{SW} / 23^{\circ} \mathrm{W}$ \\
\hline Klamath Mtns (KLMB) & $79,-5$ & 165,37 & 0.49 & 0.12 & -0.36 & 10.98 & 29 & $\mathrm{~N} 51^{\circ} \mathrm{W} / 61^{\circ} \mathrm{NE} / 21^{\circ} \mathrm{SE}$ \\
\hline Shasta (SHAS) & $75,-9$ & 149,60 & 0.45 & 0.07 & -0.69 & 7.15 & 44 & $\mathrm{~N} 45^{\circ} \mathrm{W} / 44^{\circ} \mathrm{NE} / 23^{\circ} \mathrm{E}$ \\
\hline East Shasta (ESHA) & 85,13 & $172,-12$ & 0.44 & -0.07 & -0.07 & 10.82 & 39 & $\mathrm{~N} 51^{\circ} \mathrm{W} / 72^{\circ} \mathrm{SW} / 0^{\circ} \mathrm{NW}$ \\
\hline Stephens Pass (STEP) & 91,2 & $181,-3$ & 0.52 & 0.20 & 0.02 & 5.10 & 28 & $\mathrm{~N} 44^{\circ} \mathrm{W} / 86^{\circ} \mathrm{SW} / 1^{\circ} \mathrm{NW}$ \\
\hline Medicine Lake (MEDL) & 78,4 & 170,14 & 0.48 & 0.04 & -0.07 & 10.78 & 49 & $\mathrm{~N} 55^{\circ} \mathrm{W} / 83^{\circ} \mathrm{NE} / 13^{\circ} \mathrm{SE}$ \\
\hline
\end{tabular}

${ }^{\text {a }}$ Abbreviations in parentheses refer to shear domains in Figure 3 of the main text, results from bold domain names are in Figure 2. 


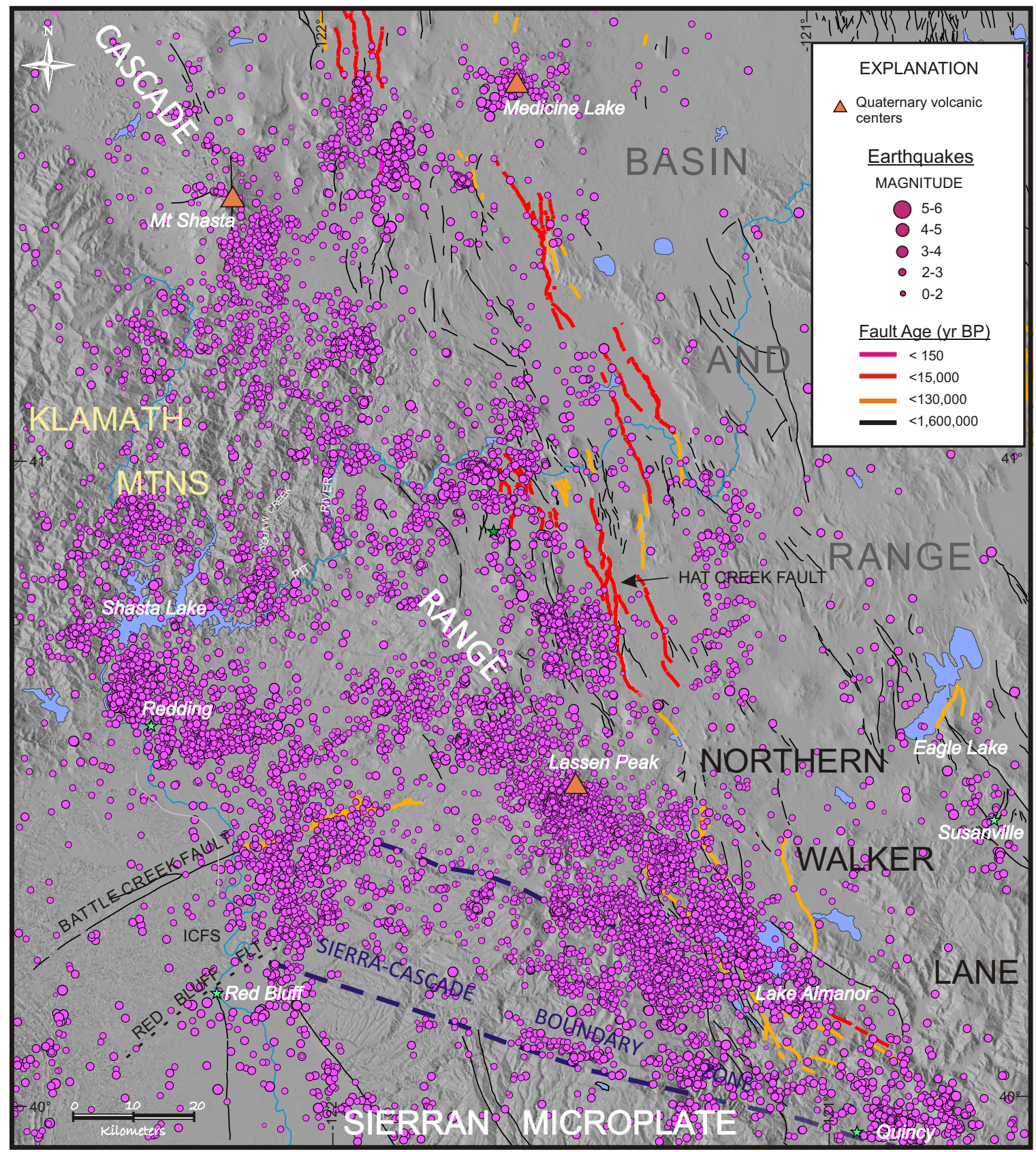

Figure S1. Earthquakes Recorded in the Study Region, 1973 - 2011. Seismicity recorded on the Northern California Seismic Network (NCSN) and archived by the Northern California Earthquake Data Center (NCEDC) for the period 1973 through 2011 is shown in this figure as purple circles, scaled in size to correspond with the magnitude. The main tectonic elements in the region are: the Klamath Mountains, the southern Cascade Range, the Basin and Range province, the northern Walker Lane, the Sierra-Cascade Boundary Zone (blue dashed line) and the Sierran microplate. The Inks Creek Fold System (ICFS) lies north of Red Bluff between the Red Bluff fault and the Battle Creek fault. 


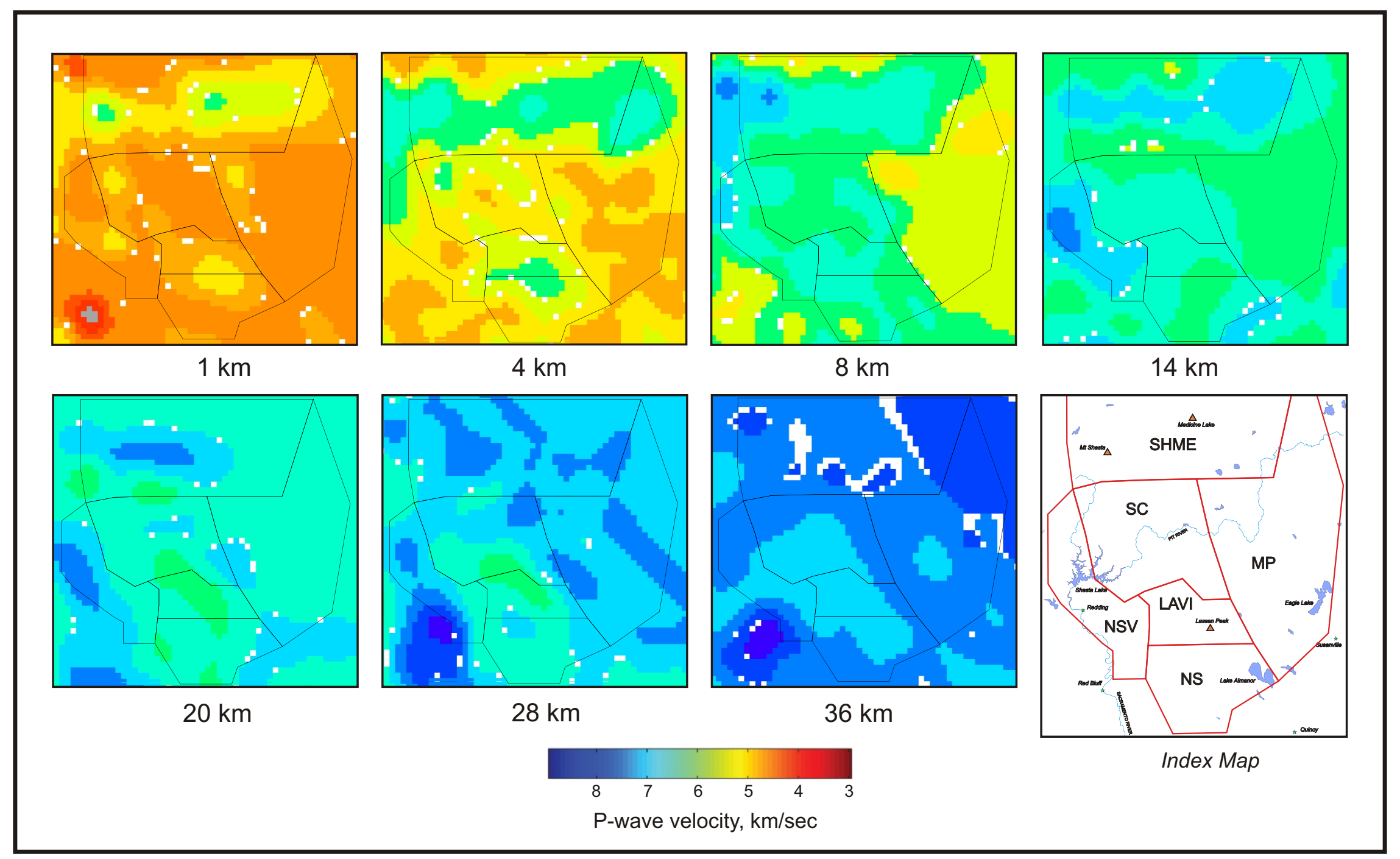

Figure S2. P-wave Velocity Domains for Northern California. A regional three-dimensional P-wave velocity model for the crust and upper mantle of northern California (Thurber et al., 2009) was used to develop one-dimensional starting models for the joint hypocentral determination program VELEST (Kissling et al., 1994). The distribution of P-wave velocities at the seven depths used by Thurber et al. (2009) are shown in this figure along with the outlines of the domains for which new velocity models were developed. 


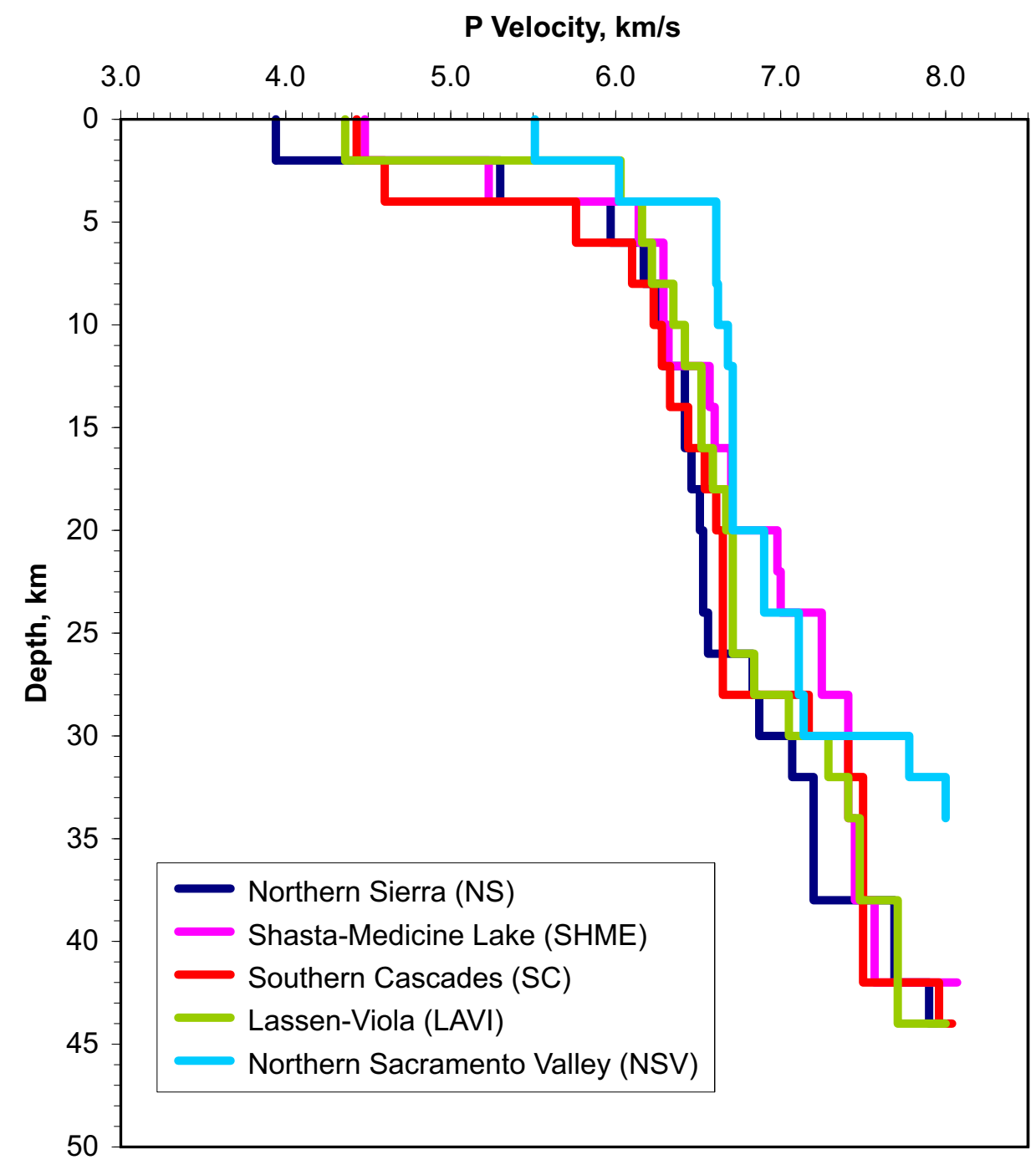

Figure S3. Final Velocity Models Developed from the Joint Hypocentral Determination Analysis. Final P-wave velocity models for the domains in Figure S2 are summarized here. These final velocity models were used to relocate earthquakes in the next phase of the analysis, the double-difference inversion. There were insufficient data and seismograph coverage to develop an independent model for the Modoc Plateau domain (MP on Figure S2). Therefore, the Southern Cascades (SC) model was used to relocate events in the western part of the Modoc Plateau. 


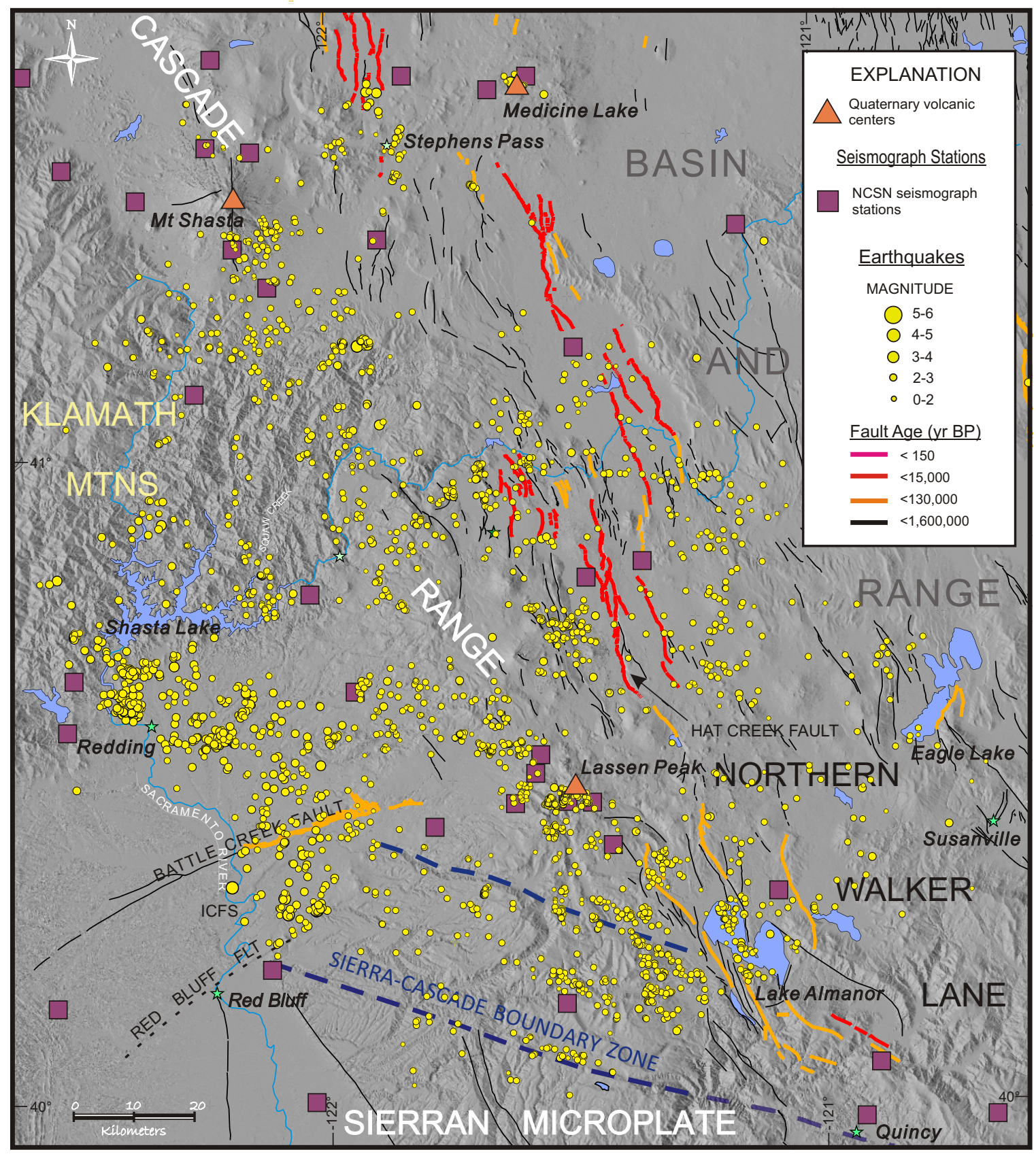

Figure S4. Seismicity in the Study Region Relocated Using Double-Difference Methodology. The yellow circles represent the epicenters of earthquakes relocated using the double-difference algorithm of Waldhauser and Ellsworth $(2000,2001)$. Purple squares show the NCSN seismograph stations operating in the region. 


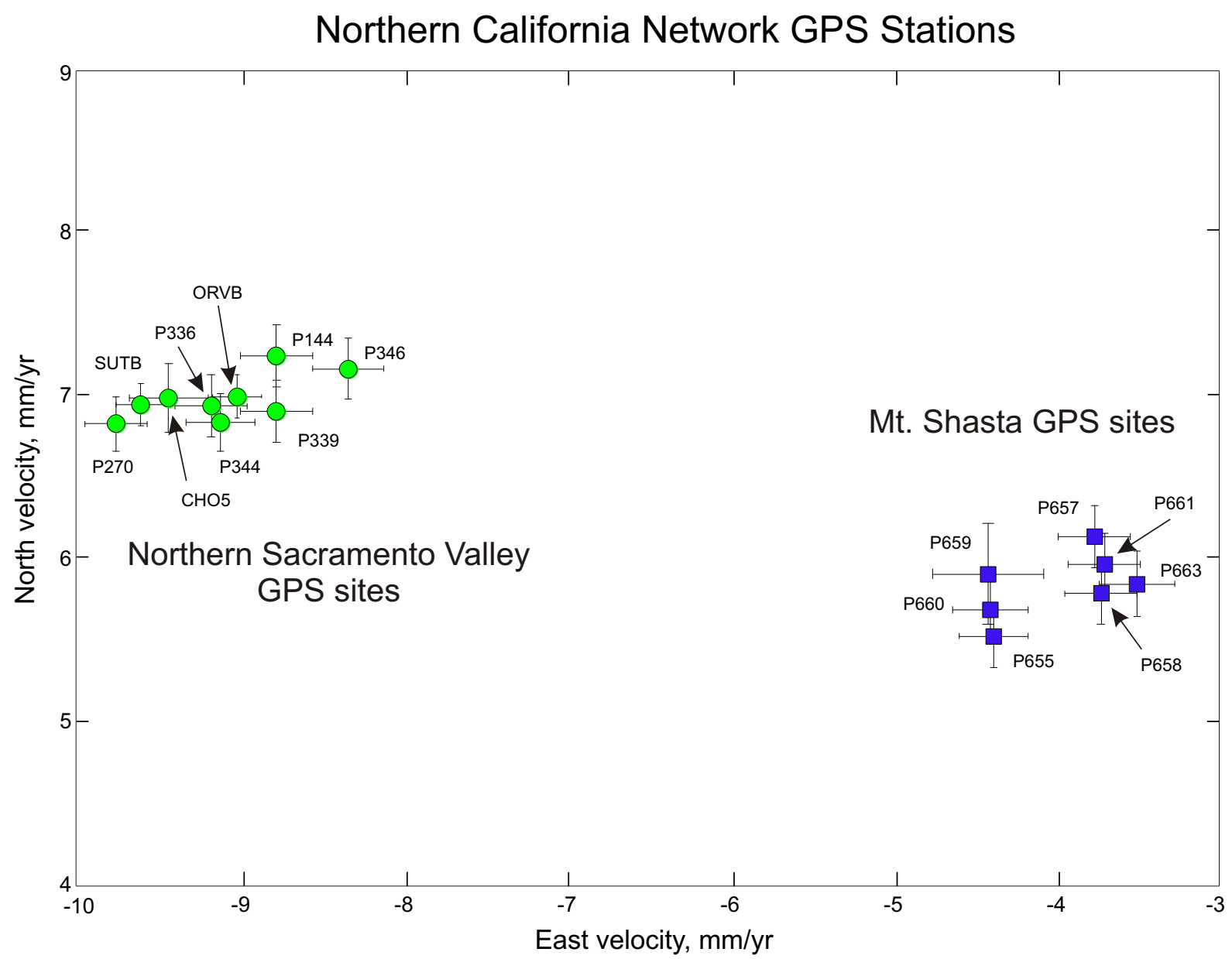

Figure S5: Differential motion between the Sierra Nevada microplate (SN) and Oregon Coast block (OCB) illustrated by the motions (relative to stable North America) of GPS stations located directly south and north of the SN-OCB boundary. Blue squares are data from GPS stations near Mt. Shasta in the OCB. Green circles are from northern Sacramento Valley GPS sites in the SN. The location of the GPS stations are shown in Figure 2. See main text for further explanation. GPS data downloaded from USGS NCalifornia network website on 23 January 2016. 